\title{
Profile of Arthritis Disability: II
}

\author{
LOIS M. VERBRUGGE ${ }^{1}$ AND LUCIA JUAREZ ${ }^{2}$
}

Objective. Arthritis is the most common chronic condition and the most common cause of disability among older US adults. We studied social participation, disabilities in many life domains, accommodations used (buffers), and accommodations needed (barriers) for US adults with arthritis disability compared with adults with disability from other conditions.

Methods. The data source is the National Health Interview Survey Disability Supplement Phase Two. Arthritis-disabled individuals named arthritis as the main cause of $\geq 1$ disabilities. Other-disabled individuals named only other conditions as causes of their disabilities. We compared outcomes for the groups, taking sample weights and complex variances into account.

Results. Arthritis-disabled individuals get out and about less often than other-disabled individuals, but they manage to maintain active social ties. They have more disabilities of all types (personal care, household management, physical tasks, transportation, home, work), and the disabilities often cause fatigue, long task time, and pain. Despite this, arthritis-disabled individuals use less personal assistance than other-disabled individuals; they do use more equipment assistance. Arthritis-disabled individuals report more barriers in getting around outside their home and at their workplace.

Conclusion. The distinctive profile of arthritis disability includes extensive and uncomfortable disabilities, yet there are active management strategies to handle these disabilities. Problems away from home and at work should inspire engineers and planners to improve public access and equipment for persons with this high-prevalence disability.

KEY WORDS. Disability; Arthritis; Accommodation; Assistance; Rehabilitation.

\section{INTRODUCTION}

Arthritis is the most common chronic condition for older adults in the US, and it ranks at or near top prevalence in midlife as well (1-3). By most measures, half or more of individuals ages $\geq 65$ years have arthritis (4-11). Arthritis is the leading cause of activity limitations in mid and late life $(2,3,12)$. Arthritis restricts work and daily activities, increases health care expenses, causes pain and sometimes

Supported by research grants from the National Center for Medical Rehabilitation Research (NIH) and the Centers for Disease Control and Prevention (DHHS). Publication charges partially funded by the University of Alabama at Birmingham Center for Education and Research on Therapeutics cooperative agreement (AHRQ, U18-HS10389). Dr. Verbrugge is recipient of a senior fellowship from the Asia Research Institute, National University of Singapore.

${ }^{1}$ Lois M. Verbrugge, PhD, MPH: Institute of Gerontology, University of Michigan, Ann Arbor, and Asia Research Institute, National University of Singapore, Singapore; ${ }^{2}$ Lucia Juarez, MA: University of Alabama, Birmingham.

Address correspondence to Lois $\mathrm{M}$. Verbrugge, $\mathrm{PhD}, \mathrm{MPH}$, Institute of Gerontology, 300 North Ingalls, University of Michigan, Ann Arbor, MI 48109-2007. E-mail: verbrugg@ umich.edu.

Submitted for publication January 28, 2005; accepted in revised form August 18, 2005. depression, and lessens quality of life (13-26). In terms of population burden, arthritis ranks high within nations and worldwide for medical costs, lost income, and lost years of disability-free life (27-36). Recent policy reports call for more research and advocacy for this common disabling condition $(37,38)$.

This report profiles US adults with arthritis disability, comparing them with adults whose disabilities are due to other conditions. We used the National Health Interview Survey Disability Supplement (NHIS-D) Phase Two. Phase Two's distinctive content is transportation, home, and work disabilities; accommodations made for disabilities in those domains; and perceived barriers in those domains. This study extends our prior analyses based on NHIS-D Phase One (39). By integrating results from both surveys, we state a more comprehensive view of arthritis disability.

\section{SUBJECTS AND METHODS}

Data source. The 1994 and 1995 National Health Interview Surveys (NHIS), conducted by the National Center for Health Statistics (NCHS), included a Disability Supplement (NHIS-D). The supplement had 2 phases. NHIS-D Phase One was conducted with the main NHIS survey, and 
provided disability information for US community dwellers of all ages. NHIS-D Phase Two was a later followup for individuals identified in Phase One as having health-related limitation or disability, and it asked detailed questions about their problems and accommodations. Analyses of Phase Two data concentrate on disability groups, not disease groups. NHIS-D does not ask about the presence or absence of a list of common chronic conditions; condition information comes from individuals' reports of what causes their disability(ies). NHIS-D questionnaires are available at the NCHS website (www.cdc.gov/nchs) and in printed form (40).

Arthritis-disabled individuals and other-disabled individuals. We studied adults (ages $\geq 18$ years) with disability due to arthritis compared with adults whose disabilities are due to other conditions. Subjects' status was determined at Phase One, where they were asked what the main condition causing disability was for 17 disability items. The items concerned personal care (activities of daily living [ADL]) and household management (instrumental activities of daily living [IADL]) difficulties due to health, physical limitations (PLIM), sensory or communication limitations, cognitive or emotional limitations, and receipt of physical or occupational therapy in the past year. We called these items target disabilities.

Arthritis-disabled individuals named arthritis as the main cause of $\geq 1$ target disabilities. We defined arthritis 2 ways, one with a wide variety of International Classification of Diseases, Ninth Revision condition codes covering arthritis and other rheumatic conditions, and the other limited to codes for arthritis (39). The first definition covers all forms of arthritis (arthropathies) such as osteoarthritis, rheumatoid arthritis, ankylosing spondylitis, and other axial types; rheumatic and connective tissue conditions such as lupus, bunion, disorders of synovium, tendon, or bursa; nonspecific rheumatism and fibromyalgia; and other-system diseases with prominent joint or connective tissue manifestations such as gout, carpal tunnel syndrome, and Raynaud's syndrome. The second definition covers only arthropathies. We used 2 codespans because some agencies and health care professionals want the broadest possible view for prevalence and disease impact, whereas others prefer information based on a more distinct set of conditions. We called the 2 groups A\&RDisab and ArthDisab, respectively.

Other-disabled individuals were the comparison group. Their disabilities are all due to conditions other than arthritis. Operationally, we selected respondents with target disability(ies) who did not name arthritis and other rheumatic conditions as a cause. We called the group OthDisab.

NCHS planned to conduct the followup soon after Phase One, but the interviews occurred over some time (19941997; mean 1.2 years). We considered identifying arthritis disability anew in Phase Two data, but all options were inferior to the Phase One classification (details available upon request from the corresponding author). Therefore, the arthritis-disabled and other-disabled groups were viewed as cohorts with initial and followup reports about their lives.

Nearly two-thirds of Phase One respondents were rein- terviewed in Phase Two (61.5\% A\&RDisab, 62.6\% ArthDisab, 62.4\% OthDisab). Besides typical reasons for noninterview (deceased, unable to contact, institutionalized, refused), Phase Two was not conducted for part of the 1995 Phase One sample due to budget constraints. In comparison with the entire initial sample using their Phase One information, followup respondents in each group were slightly older and were more often female (Table 1). Race and education were closely comparable. Followup respondents had poorer health, less work activity, and stronger self identity as a person with disability, compared with whole samples. In summary, NHIS-D excelled in keeping respondents who were women, older, and in poor health from the first to second interview.

Variables. Phase Two had many questions about social participation, disabilities, buffers, and barriers. Social participation refers to involvement and integration in one's community. We studied transportation behavior, social contacts and outings, and work and volunteer activities. Disabilities are defined as having health-related difficulty performing daily physical and role activities. Respondents were asked about disability for personal care (ADL), household management (IADL), physical limitations (PLIM), transportation, home, and work (details in Tables 3-6 footnotes). ADL, IADL, and PLIM disabilities were also queried in Phase One, but the question wordings were very different. Accommodations used to help relieve disability are called buffers. Respondents were asked about buffers for ADL, IADL, transportation, and work disabilities. ADL buffers are equipment and personal assistance. IADL buffers are personal assistance. Transportation and work buffers are special equipment and arrangements that help with getting around and working a paid job. Health services use can be viewed as a general buffer that helps persons with disabilities; therefore, we studied that as well. Accommodations that individuals need but do not have are called barriers. Respondents were asked about barriers for ADL, IADL, transportation, housing, and work. Needed health services were also studied.

Procedures. NHIS-D had a multistage, cluster probability sample of US households $(40,41)$. The design affects point estimates and their variances. We used NCHS-provided weights to generate correct point estimates and the statistical software SUDAAN 7.5.3 for correct variances (42). There were $<0.4 \%$ missing data (Don't know, Refused, Not ascertained) for almost all items; we assigned the mode.

Means and percents for outcome variables were computed for the study groups (A\&RDisab, ArthDisab, OthDisab). We performed pairwise tests to find statistically significant differences between arthritis-disabled and other-disabled individuals.

\section{RESULTS}

We compared demographic features, social participation, disabilities, buffers, and barriers of arthritis-disabled individuals and other-disabled individuals. All stated differ- 


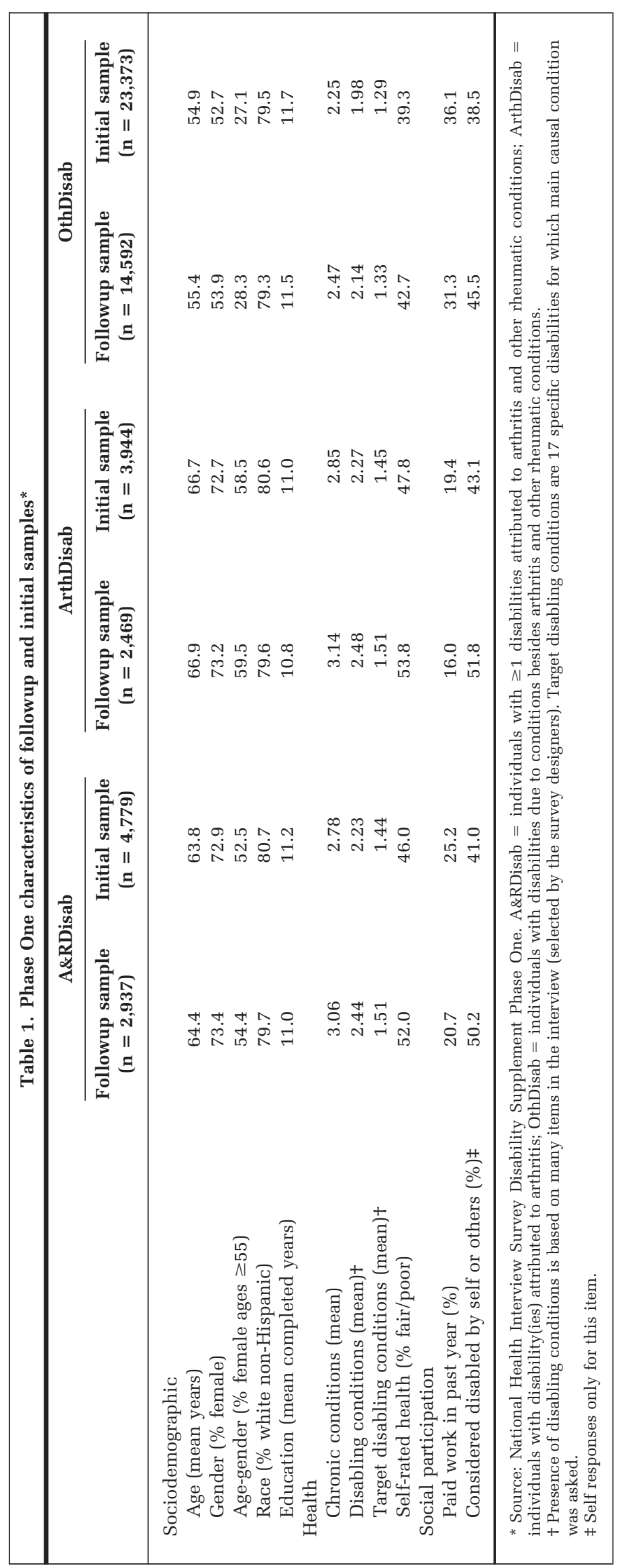




\begin{tabular}{|c|c|c|c|c|c|}
\hline Characteristic & A\&RDisab & ArthDisab & OthDisab & $\begin{array}{c}\text { A\&RDisab vs } \\
\text { OthDisabt }\end{array}$ & $\begin{array}{c}\text { ArthDisab vs } \\
\text { OthDisabt }\end{array}$ \\
\hline Age (mean years) & 65.6 & 68.0 & 56.5 & $P \leq 0.001$ & $P \leq 0.001$ \\
\hline Gender (\% female) & 73.4 & 73.2 & 53.9 & $P \leq 0.001$ & $P \leq 0.001$ \\
\hline Age-gender ( $\%$ female ages $\geq 55$ ) & 55.7 & 60.7 & 29.1 & $P \leq 0.001$ & $P \leq 0.001$ \\
\hline \multicolumn{6}{|c|}{$\begin{array}{l}\text { * Source: National Health Interview Survey Disability Supplement Phase Two. Data weighted to be representative of the US civilian noninstitutional } \\
\text { population ages } \geq 18 \text {; complex variances estimated. A\&RDisab }=\text { individuals with } \geq 1 \text { disabilities attributed to arthritis and other rheumatic conditions } \\
\text { ArthDisab = individuals with disability(ies) attributed to arthritis; OthDisab = individuals with all disabilities due to conditions besides arthritis and } \\
\text { other rheumatic conditions; vs = versus. } \\
\text { † Pairwise significance tests. }\end{array}$} \\
\hline
\end{tabular}

ences were statistically significant ( $P<0.05$ or stronger). Some differences are numerically small; we note these in the text. We use the term "arthritis disability" to encompass A\&RDisab and ArthDisab, because comparisons of the 2 arthritis groups with other-disabled individuals proved very similar.

Demographic features. Arthritis-disabled individuals were $\sim 10$ years older than other-disabled individuals on average, and were more likely to be female (Table 2). The majority (56-61\%) of arthritis-disabled individuals were women ages $\geq 55$ years, compared with approximately one-third $(29 \%)$ of the other-disabled group.

Social participation. Arthritis-disabled individuals made fewer local vehicle-based trips and fewer long distance trips (difference numerically small) than other-disabled individuals (Table 3). Arthritis-disabled individuals leave the house fewer days each week. However, they are very sociable, having more friend/neighbor/relative contacts (difference numerically small) by phone or in person. All groups were similar for going to events such as religious services, movies or clubs, or restaurants. Arthritis-disabled individuals were slightly more satisfied (difference numerically small) with their level of social activities than were other-disabled individuals. Arthritis-disabled individuals were less often employed or in job preparation activities, and more often said they were retired. Levels of volunteer work were similar for all groups.

Disabilities. Arthritis-disabled individuals had more ADL and IADL disabilities than did other-disabled individuals (Table 4). Arthritis-disabled individuals were more bothered by tiredness, taking a long time, and pain in their ADL and especially IADL tasks. Yet their ADL/IADL disabilities were similar in severity (degree of difficulty) and shorter in duration compared with other-disabled individuals. The situation was quite different for PLIM. Arthritis-disabled individuals not only had more physical limitations, but severity was higher and duration was longer. Arthritisdisabled individuals also had more problems in other life domains: they reported more transportation problems (difference numerically small) and notably more home access problems due to health. Higher percentages of arthritisdisabled individuals said their health prevents work, they are retired due to disability/health, and they cannot work even with accommodations. In contrast, other-disabled in- dividuals reported more problems attaining and keeping a job due to their health (difference numerically small). Overall, arthritis-disabled individuals had problems in more life domains, and their disability was more extensive.

Buffers for disability. Despite having more ADL and IADL disabilities, arthritis-disabled individuals reported using less personal assistance for ADL/IADL than otherdisabled individuals (Table 5). The arthritis groups do use more equipment assistance (ADL; not asked for IADL). Taking all assistance into account, arthritis-disabled individuals had less total assistance for their ADL (difference numerically small) and IADL disabilities. Availability of special transportation equipment or services was similar for the groups. Arthritis-disabled individuals have more special features installed for them at their workplace, and have received less vocational rehabilitation than otherdisabled individuals.

Arthritis-disabled individuals used more medical devices, were more likely to have implants, had more prescription medicines to take, made more recent visits to their regular physician, and more often had a coordinator who helps with medical care. In contrast, other-disabled individuals had more mental health services, made more recent visits to specialists, and more often had a coordinator for nonmedical services (difference numerically small). The groups were similar for use of allied health services. Overall, arthritis-disabled individuals had more extensive buffers in their lives. Accommodations existed in more daily activities, and they had more types of health services.

Barriers in disability. Phase Two had many questions about barriers, but not many respondents reported barriers. The groups had similar wishes for more ADL/IADL assistance (Table 6). They cited similar barriers for transportation and housing, with an important exception: arthritis-disabled individuals were much more likely to report problems getting around outside their home. Their reasons were fear, weather, poor access to mobility equipment, not having someone to help, and unable to walk. Arthritis-disabled individuals also reported needing special features at their workplace, more than other-disabled workers. Arthritis-disabled individuals said they have less need for vocational rehabilitation (difference numerically small). All groups were similar for health services needs 


\begin{tabular}{|c|c|c|c|c|c|}
\hline & A\&RDisab & ArthDisab & OthDisab & $\begin{array}{l}\text { A\&RDisab vs } \\
\text { OthDisabt }\end{array}$ & $\begin{array}{c}\text { ArthDisab vs } \\
\text { OthDisabt }\end{array}$ \\
\hline \multicolumn{6}{|l|}{ Transportation behavior } \\
\hline Any vehicular travel in past 6 months (\%) & 88.8 & 88.3 & 90.4 & $P \leq 0.05$ & $P \leq 0.01$ \\
\hline Local trips in vehicles in past week (mean) & 6.5 & 6.0 & 8.1 & $P \leq 0.001$ & $P \leq 0.001$ \\
\hline Any trips $(\%)$ & 82.4 & 81.6 & 85.1 & & \\
\hline$\geq 8(\%)$ & 30.3 & 26.9 & 39.0 & & \\
\hline Long-distance trips in past 6 months (mean) & 0.5 & 0.5 & 0.6 & $P \leq 0.05$ & $P \leq 0.001$ \\
\hline Any trips $(\%)$ & 16.8 & 15.4 & 18.0 & & \\
\hline \multicolumn{6}{|l|}{ Social activities } \\
\hline Days outside house in past 2 weeks (mean) & 9.3 & 8.9 & 10.5 & $P \leq 0.001$ & $P \leq 0.001$ \\
\hline Any days (\%) & 94.9 & 94.2 & 95.9 & & \\
\hline $1-7$ days $(\%)$ & 34.7 & 37.3 & 24.8 & & \\
\hline All $14(\%)$ & 49.6 & 46.3 & 62.0 & & \\
\hline $\begin{array}{l}\text { Friend/neighbor/relative contacts in past } 2 \text { weeks } \\
\text { (mean) }\end{array}$ & 20.3 & 20.0 & 18.6 & $P \leq 0.001$ & $P \leq 0.001$ \\
\hline$>10$ contacts $(\%)$ & 66.2 & 65.7 & 61.4 & & \\
\hline $\begin{array}{l}\text { Types of friend/neighbor/relatives contact in past } \\
2 \text { weeks ( } 4 \text { types, mean)‡ }\end{array}$ & 3.0 & 3.0 & 2.9 & $P \leq 0.001$ & $P \leq 0.05$ \\
\hline All 4 types $(\%)$ & 42.3 & 41.9 & 41.7 & & \\
\hline Away-from-home events in past 2 weeks (mean) & 11.4 & 11.4 & 11.1 & NS & NS \\
\hline$>10$ activities $(\%)$ & 41.4 & 40.9 & 39.4 & & \\
\hline $\begin{array}{l}\text { Types of away-from-home events in past } 2 \text { weeks } \\
\text { ( } 3 \text { types, mean)§ }\end{array}$ & 1.2 & 1.2 & 1.2 & NS & $P \leq 0.01$ \\
\hline All 3 types $(\%)$ & 10.6 & 9.6 & 11.3 & & \\
\hline $\begin{array}{l}\text { Satisfaction with social activities (\% "about } \\
\text { enough”) }\end{array}$ & 58.8 & 59.4 & 57.5 & $P \leq 0.001$ & $P \leq 0.001$ \\
\hline \multicolumn{6}{|l|}{ Productive activity } \\
\hline \multicolumn{6}{|l|}{ Current employment status (ages $\geq 18, \%$ ) } \\
\hline Working & 20.0 & 15.1 & 32.5 & $P \leq 0.001$ & $P \leq 0.001$ \\
\hline Retired & 49.0 & 53.1 & 37.8 & & \\
\hline \multicolumn{6}{|l|}{ Current activity (ages $<70, \%$ ) } \\
\hline Competitive employment & 31.8 & 25.4 & 43.4 & $P \leq 0.001$ & $P \leq 0.001$ \\
\hline Job training & 0.4 & 0.4 & 1.2 & $P \leq 0.001$ & $P \leq 0.001$ \\
\hline School & 1.8 & 1.3 & 3.7 & $P \leq 0.001$ & $P \leq 0.001$ \\
\hline Volunteer work & 13.2 & 11.8 & 11.4 & NS & NS \\
\hline Volunteer work (days per month, mean) & 0.95 & 0.92 & 0.92 & NS & NS \\
\hline \multicolumn{6}{|c|}{$\begin{array}{l}\text { * Source: National Health Interview Survey Disability Supplement (NHIS-D) Phase Two. Data weighted to be representative of the US civilian } \\
\text { noninstitutional population ages } \geq 18 \text {; complex variances estimated. A\&RDisab }=\text { individuals with } \geq 1 \text { disabilities attributed to arthritis and other } \\
\text { rheumatic conditions; ArthDisab }=\text { individuals with disability(ies) attributed to arthritis; OthDisab }=\text { individuals with all disabilities due to conditions } \\
\text { besides arthritis and other rheumatic conditions; vs = versus; NS }=\text { not significant }(P>0.05) \text {. } \\
\text { † Pairwise significance tests. Absence of significance information means that tests were not performed for the variable. } \\
\text { ₹ Contacts are in person with friends/neighbors, phone with friends/neighbors, in person with relatives, and phone with relatives. } \\
\text { § Events are going to religious place for worship/other activities; going to movie, sports event, club, class, or other group event; and going out to eat } \\
\text { at a restaurant. } \\
\text { II Includes contacts and events. Self responses only for this item. }\end{array}$} \\
\hline
\end{tabular}

(except other-disabled individuals wanted more mental health services; difference numerically small). Overall, arthritis-disabled individuals encountered barriers in more activity domains of daily life than other-disabled individuals, but reported less need for additional medical and health services (difference numerically small).

Age-sex standardized differences. Because the arthritisdisabled group was older and more female than the otherdisabled group, we also computed age-sex standardized values for all variables and performed pairwise tests for these variables. The standard population was the age-sex distribution for A\&RDisab persons at Phase Two. The standardization procedure is in SUDAAN and reweights data to the selected population distribution. We prepared tables showing both nonstandardized and standardized results side by side. To comply with this journal's specifications, we had to trim tables to show either one set or the other. We opted for the nonstandardized results (actual groups of US adults) and summarize here the standardized ones (hypothetical groups); the original full tables are available upon request. We expected that differentials would narrow with standardization, but were keen to see which ones remained steady and strong.

With standardization, most differentials still appeared, but were smaller and had lower significance levels. The strongest initial ones were robust; they stayed strong and significant when standardized. For social participation, arthritis-disabled individuals had less employment than other-disabled individuals. For disability, the entire pat- 


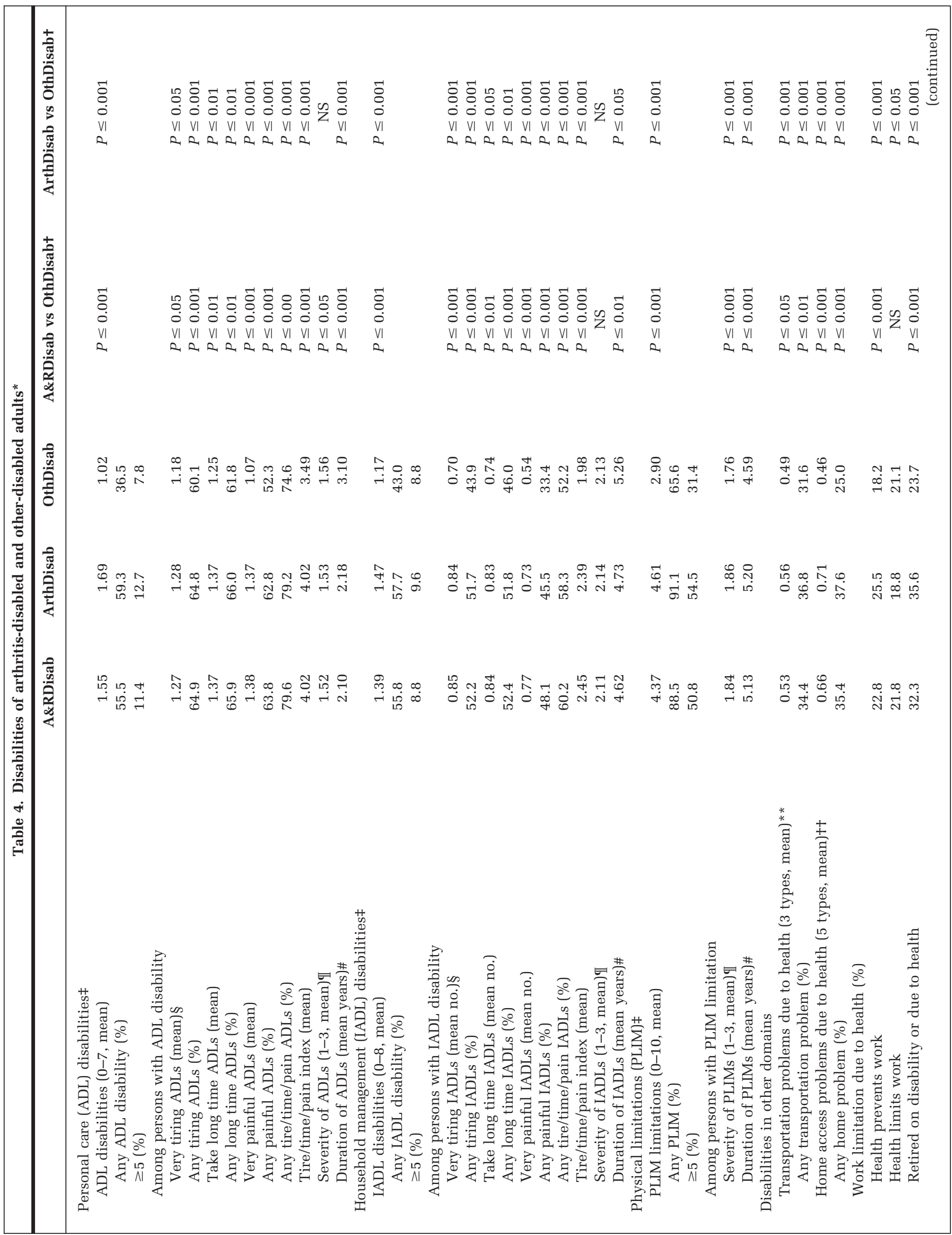




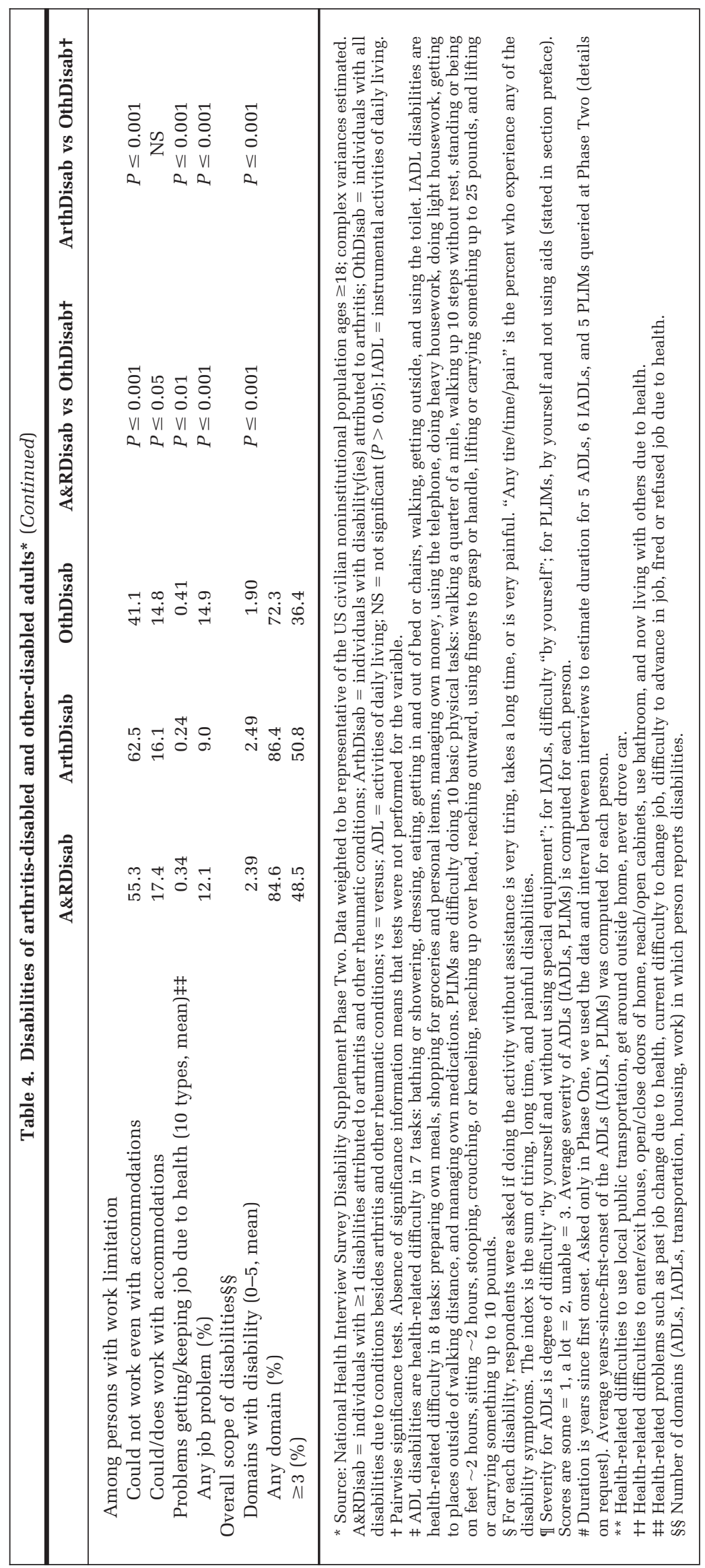


Table 5. Buffers used by arthritis-disabled and other-disabled adults*

\begin{tabular}{|c|c|c|c|c|c|}
\hline & A\&RDisab & ArthDisab & OthDisab & $\begin{array}{c}\text { A\&RDisab vs } \\
\text { OthDisabt }\end{array}$ & $\begin{array}{c}\text { ArthDisab vs } \\
\text { OthDisabt }\end{array}$ \\
\hline \multicolumn{6}{|l|}{ ADL assistance } \\
\hline \multicolumn{6}{|l|}{ Among persons with ADL disability } \\
\hline Personal assistance (mean no. ADLs)‡ & 0.89 & 0.92 & 1.26 & $P \leq 0.001$ & $P \leq 0.001$ \\
\hline Any personal assistance (\%) & 34.9 & 35.9 & 42.3 & $P \leq 0.001$ & $P \leq 0.001$ \\
\hline Hands-on help (mean) & 0.85 & 0.88 & 1.18 & $P \leq 0.001$ & $P \leq 0.001$ \\
\hline Any hands-on help (\%) & 33.2 & 34.3 & 40.2 & $P \leq 0.001$ & $P \leq 0.001$ \\
\hline Supervise/nearby help (mean) & 0.26 & 0.28 & 0.32 & $P \leq 0.05$ & NS \\
\hline Any supervise/nearby help (\%) & 14.2 & 14.7 & 17.4 & $P \leq 0.01$ & $P \leq 0.05$ \\
\hline Equipment assistance (mean no. ADLs)‡ & 1.58 & 1.66 & 1.43 & $P \leq 0.01$ & $P \leq 0.001$ \\
\hline Any equipment assistance (\%) & 60.9 & 63.4 & 54.7 & $P \leq 0.001$ & $P \leq 0.001$ \\
\hline ADL assistance index (mean)§ & 2.69 & 2.82 & 2.93 & $P \leq 0.05$ & NS \\
\hline \multicolumn{6}{|l|}{ IADL assistance } \\
\hline \multicolumn{6}{|l|}{ Among persons with IADL disability } \\
\hline Personal assistance (mean no. IADLs)‡ & 2.22 & 2.30 & 2.52 & $P \leq 0.001$ & $P \leq 0.01$ \\
\hline Any personal assistance (\%) & 82.0 & 82.7 & 82.7 & NS & NS \\
\hline Hands-on help (mean no.) & 1.89 & 1.96 & 2.15 & $P \leq 0.001$ & $P \leq 0.01$ \\
\hline Any hands-on help (\%) & 72.1 & 73.2 & 72.3 & NS & NS \\
\hline Supervise/nearby help (mean) & 0.10 & 0.11 & 0.15 & $P \leq 0.001$ & $P \leq 0.01$ \\
\hline Any supervise/nearby help (\%) & 7.0 & 7.4 & 10.0 & $P \leq 0.001$ & $P \leq 0.001$ \\
\hline IADL assistance index (mean)§ & 1.99 & 2.06 & 2.30 & $P \leq 0.001$ & $P \leq 0.001$ \\
\hline \multicolumn{6}{|l|}{ Transportation } \\
\hline Special equipment on car or other motor vehicle (\% any) & 1.1 & 1.2 & 1.6 & $P \leq 0.05$ & NS \\
\hline Community has special transportation services (\% yes) & 73.1 & 72.2 & 72.6 & NS & NS \\
\hline \multicolumn{6}{|l|}{ Work } \\
\hline \multicolumn{6}{|l|}{ Among currently employed peopleI } \\
\hline Special features at work (\% any) & 8.6 & 8.6 & 4.5 & $P \leq 0.01$ & $P \leq 0.05$ \\
\hline Special equipment or arrangements at work, \% any & 2.6 & 2.9 & 2.8 & NS & NS \\
\hline Vocational rehabilitation services ever received (15 types, mean) & 0.36 & 0.33 & 0.49 & $P \leq 0.001$ & $P \leq 0.001$ \\
\hline Any services (\%) & 17.9 & 16.6 & 20.8 & $P \leq 0.01$ & $P \leq 0.001$ \\
\hline \multicolumn{6}{|l|}{ Medical and other health services } \\
\hline Medical devices used in past 12 months (15 types, mean) & 1.01 & 1.10 & 0.79 & $P \leq 0.001$ & $P \leq 0.001$ \\
\hline Any devices (\%) & 51.2 & 54.5 & 40.8 & $P \leq 0.001$ & $P \leq 0.001$ \\
\hline Medical implants used now (11 types, mean) & 0.34 & 0.25 & 0.23 & $P \leq 0.001$ & $P \leq 0.001$ \\
\hline Any implants (\%) & 26.6 & 29.2 & 19.1 & $P \leq 0.001$ & $P \leq 0.001$ \\
\hline Prescription medicines to take ( $\%$ any) & 86.3 & 88.3 & 73.5 & $P \leq 0.001$ & $P \leq 0.001$ \\
\hline$\geq 6$ prescription medicines $(\%)$ & 15.7 & 20.6 & 11.0 & & \\
\hline Visits to regular physician in past 3 months (mean) & 1.62 & 1.60 & 1.33 & $P \leq 0.001$ & $P \leq 0.001$ \\
\hline Visits to specialists in past 3 months (mean) & 0.91 & 0.86 & 1.06 & $P \leq 0.05$ & $P \leq 0.01$ \\
\hline Allied health services used in past 12 months (\% any) & 23.7 & 23.5 & 21.6 & $P \leq 0.05$ & $P \leq 0.05$ \\
\hline Mental health services used in past 12 months (\% any) & 5.4 & 4.6 & 9.6 & $P \leq 0.001$ & $P \leq 0.001$ \\
\hline Coordinator for medical care (\% have) & 52.3 & 52.8 & 47.3 & $P \leq 0.001$ & $P \leq 0.001$ \\
\hline Coordinator for nonmedical services (\% have) & 6.3 & 6.8 & 7.9 & $P \leq 0.01$ & NS \\
\hline \multicolumn{6}{|l|}{ Overall scope of disability buffers\# } \\
\hline Activity domains with buffers (0-4, mean) & 0.92 & 0.98 & 0.68 & $P \leq 0.001$ & $P \leq 0.001$ \\
\hline Any domain (\%) & 60.2 & 63.5 & 44.4 & & \\
\hline$\geq 2$ domains $(\%)$ & 30.6 & 33.2 & 22.0 & & \\
\hline Medical domains with buffers (0-11, mean) & 3.83 & 3.92 & 3.40 & $P \leq 0.001$ & $P \leq 0.001$ \\
\hline Any domain (\%) & 95.5 & 96.1 & 89.6 & & \\
\hline$\geq 5$ domains (\%) & 35.0 & 36.5 & 30.0 & & \\
\hline
\end{tabular}

* Source: National Health Interview Survey Disability Supplement Phase Two. Data weighted to be representative of the U.S. civilian noninstitutional population ages $\geq 18$; complex variances estimated. A\&RDisab = individuals with $\geq 1$ disabilities attributed to arthritis and other rheumatic conditions; ArthDisab = individuals with disability(ies) attributed to arthritis; OthDisab = individuals with all disabilities due to conditions besides arthritis and other rheumatic conditions; vs = versus; ADL = activities of daily living; NS = not significant $(P>0.05)$; IADL = instrumental activities of daily living. + Pairwise significance tests. Absence of significance information means that tests were not performed for the variable.

¥ Personal assistance ("receive help from another person") has 2 types: "hands-on help" and "supervises or stays nearby." Equipment assistance is "special equipment or aids."

$\S$ ADL assistance index is sum of tasks with hands-on, supervise/nearby, or equipment help (range 0-21). IADL assistance index is sum of tasks with hands-on or supervise/nearby help (range 0-16).

II Special features are installed items such as handrails, regular or adapted elevator, adapted work station, and adapted restroom (7 types). Special equipment or arrangements are specialized disability aids such as voice synthesizer, job coach or personal assistant for work tasks, sign language interpreter, special office supplies, and changes in work duties and work hours (10 types).

\# Number of domains in which person reports buffers. The activity domains are ADLs, IADLs, transportation, work. The medical domains are the 9 shown above, plus center-based services and medical treatments at home (tiny percents with no group differences). 
Table 6. Barriers for arthritis-disabled and other-disabled adults*

\begin{tabular}{|c|c|c|c|c|c|}
\hline & A\&RDisab & ArthDisab & OthDisab & $\begin{array}{l}\text { A\&RDisab vs } \\
\text { OthDisabt }\end{array}$ & $\begin{array}{l}\text { ArthDisab vs } \\
\text { OthDisabt }\end{array}$ \\
\hline \multicolumn{6}{|l|}{ ADLs and IADLs } \\
\hline \multicolumn{6}{|l|}{ Among persons with ADL disability } \\
\hline Need (more) hands-on help for ADLs (\%) & 8.5 & 8.6 & 8.4 & NS & NS \\
\hline Need (more) supervise/nearby help (\%) & 3.7 & 3.6 & 3.7 & NS & NS \\
\hline \multicolumn{6}{|l|}{ Among persons with IADL disability } \\
\hline Need (more) hands-on help for IADLs (\%) & 19.0 & 18.7 & 15.6 & $P \leq 0.05$ & $P \leq 0.05$ \\
\hline Need (more) supervise/nearby help (\%) & 4.6 & 4.8 & 4.1 & NS & NS \\
\hline \multicolumn{6}{|l|}{ Transportation } \\
\hline $\begin{array}{l}\text { Need special equipment for car or other motor vehicle } \\
(\%)\end{array}$ & 1.4 & 1.3 & 1.0 & NS & NS \\
\hline $\begin{array}{l}\text { Barriers to using community special transportation } \\
\text { services ( } \% \text { any barrier) }\end{array}$ & 5.4 & 5.6 & 4.8 & NS & NS \\
\hline $\begin{array}{l}\text { Barriers to using local public transportation (\% any } \\
\text { barrier) }\end{array}$ & 13.2 & 14.4 & 10.8 & $P \leq 0.01$ & NS \\
\hline $\begin{array}{l}\text { Barriers to getting around outside home due to health (\% } \\
\text { any barrier) }\end{array}$ & 28.8 & 31.2 & 21.5 & $P \leq 0.001$ & $P \leq 0.001$ \\
\hline \multicolumn{6}{|l|}{ Housing } \\
\hline Home has elevated features (\%) & 76.2 & 75.1 & 76.8 & NS & NS \\
\hline \multicolumn{6}{|l|}{ Work } \\
\hline \multicolumn{6}{|l|}{ Among currently employed personsł } \\
\hline Need and do not have special features at work (\%) & 13.3 & 14.8 & 6.2 & $P \leq 0.001$ & $P \leq 0.001$ \\
\hline $\begin{array}{l}\text { Need and do not have special equipment or } \\
\text { arrangements at work }(\%)\end{array}$ & 0.3 & 0.4 & 1.0 & $P \leq 0.01$ & NS \\
\hline Need (more) vocational rehabilitation services (\%) & 5.3 & 4.0 & 6.7 & $P \leq 0.05$ & $P \leq 0.001$ \\
\hline \multicolumn{6}{|l|}{ Medical and other health services } \\
\hline $\begin{array}{l}\text { Needed and did not receive allied health services in past } \\
12 \text { months (\%) }\end{array}$ & 3.8 & 3.8 & 3.6 & NS & NS \\
\hline $\begin{array}{l}\text { Needed and did not receive mental health services in } \\
\text { past } 12 \text { months (\%) }\end{array}$ & 1.7 & 1.5 & 3.0 & $P \leq 0.001$ & $P \leq 0.001$ \\
\hline $\begin{array}{l}\text { Needed and did not have coordinator for nonmedical } \\
\text { services in past } 12 \text { months }(\%)\end{array}$ & 1.1 & 1.0 & 1.1 & NS & NS \\
\hline \multicolumn{6}{|l|}{ Overall scope of disability barriers§ } \\
\hline Activity domains with barriers (0-6, mean) & 1.46 & 1.48 & 1.31 & $P \leq 0.001$ & $P \leq 0.001$ \\
\hline Any domain (\%) & 87.0 & 86.7 & 84.9 & & \\
\hline$\geq 3$ domains (\%) & 14.1 & 15.0 & 11.3 & & \\
\hline Medical domains with barriers (0-5, mean) & 0.14 & 0.12 & 0.17 & $P \leq 0.01$ & $P \leq 0.001$ \\
\hline Any domain (\%) & 10.7 & 9.6 & 12.7 & & \\
\hline \multicolumn{6}{|c|}{$\begin{array}{l}\text { * Source: National Health Interview Survey Disability Supplement Phase Two. Data weighted to be representative of the US civilian noninstitutional } \\
\text { population ages } \geq 18 ; \text { complex variances estimated. A\&RDisab }=\text { individuals with } \geq 1 \text { disabilities attributed to arthritis and other rheumatic conditions; } \\
\text { ArthDisab = individuals with disability(ies) attributed to arthritis; OthDisab = individuals with all disabilities due to conditions besides arthritis and } \\
\text { other rheumatic conditions; vs = versus; ADL }=\text { activities of daily living; NS = not significant }(P>0.05) \text {; IADL = instrumental activities of daily living. } \\
\text { + Pairwise significance tests. Absence of significance information means that tests were not performed for the variable. } \\
\text { ₹ Special features are installed items such as handrails, regular or adapted elevator, adapted work station, and adapted restroom ( } 7 \text { types). Special } \\
\text { equipment or arrangements are specialized disability aids such as voice synthesizer, job coach or personal assistant for work tasks, sign language } \\
\text { interpreter, special office supplies, and changes in work duties and work hours (10 types). } \\
\text { § Number of domains in which person reports barriers. The activity domains are ADLs, IADLs, transportation, getting about outside house, housing, } \\
\text { and work. The medical domains are vocational rehabilitation, allied health services, center-based services (not shown due to tiny percents), mental } \\
\text { health services, and coordinator for nonmedical services. }\end{array}$} \\
\hline
\end{tabular}

tern of more disabilities, more botheration from fatigue/ taking a long time/pain, and the severity/duration differences remained strong and significant (one exception: no standardized difference in IADL disabilities). Problems with home access were greater for arthritis-disabled individuals. For buffers, arthritis-disabled individuals' lesser use of personal assistance, greater use of equipment assistance, and distinctive health services profile persisted after standardization. Arthritis-disabled individuals' barriers to getting around outside of the home and need for special features at work also remained. Overall, disabilities, accommodations, and barriers spread into more arenas of daily life for arthritis-disabled individuals than for those with other disabling conditions. In short, the profile of arthritis disability stayed the same after age-sex adjustment.

We note that our analysis is not multivariate, identifying covariates that affect outcomes. Instead, we present descriptive group differences, and the standardization offers a view of those differences with 2 important factors removed. 


\section{DISCUSSION}

The Phase Two analyses offer new views of arthritis disability that are not available from Phase One data. Phase Two concentrated on problems in transportation, home access, social activities, work, and medical/health services. Respondents were queried about ADL, IADL, and PLIM disabilities in both Phases, but the questions differed; therefore, Phase Two analyses provide some new views about these disabilities as well. Our results are robust, occurring in both nonstandardized and age-standardized differentials. We discuss here prominent features of arthritis disability from the Phase Two analyses.

First, arthritis-disabled individuals are out and about less than individuals with disability from other conditions. They leave the house on fewer days, make fewer local trips and long-distance trips (difference numerically small), and are less often employed or making efforts to find a job. Yet they maintain social ties, with more informal contacts by phone or in person (difference numerically small). And their frequency of outings for entertainment, clubs, and restaurants is similar to the otherdisabled group. These results imply that arthritis-disabled individuals have narrower spatial zones of activity that are more restricted to local places such as friends' homes and nearby stores/cafés.

Second, arthritis-disabled individuals have more disabilities of all types (PLIM, ADL, IADL, transportation [difference numerically small], home, work) than do otherdisabled individuals. The greatest disadvantage for arthritis-disabled individuals is in PLIM. These basic tasks are physical "building blocks" for roles/activities (43). Physical limitations can have far-reaching effects on a person's ability to participate in obligatory and discretionary activities. Arthritis-disabled individuals have higher numbers, higher severity, and longer durations of PLIM than otherdisabled individuals, so their disadvantage is large and long. For ADL and IADL, the arthritis groups more often have bothersome symptoms such as fatigue, taking a long time, and pain when performing disability tasks. ADL/ IADL severity is rated lower and duration is shorter, but the real burden resides in everyday uncomfortable effort to complete the tasks. More transportation, home, and work problems due to health signal the long stretch of arthritis disability in daily life.

Third, arthritis-disabled individuals use less assistance for their disabilities. They have much less personal help for ADL/IADL disabilities, but they do use equipment more often. Arthritis-disabled individuals use regular health services more often, and specialized services less often, than other-disabled individuals. Therefore, despite higher levels of disability, arthritis-disabled individuals are managing with less assistance than other-disabled individuals. In terms of the disablement process, it appears they are inserting suitable buffers into daily life to offset problems that their physical limitations cause in going places and performing activities (43).

Fourth, arthritis-disabled individuals identify 2 zones with barriers: getting outside for away-from-home activities and needing basic accommodations at their workplace. Staying at home can prompt functional declines
(44), and unmodified workplaces can cause discomfort and even job cessation. In other respects, unmet needs of arthritis-disabled and other-disabled individuals are similar.

Last, disability penetrates life much more broadly for arthritis-disabled individuals than for other-disabled individuals. Disabilities stretch into more activity domains for persons with arthritis disability. Not surprisingly, buffers and barriers stretch farther also as these individuals try to accommodate, sometimes successfully, sometimes not.

The combined results of Phases One (39) and Two demonstrate the far reach of disability for arthritis-disabled individuals in daily life, and their vigorous and extensive efforts to manage those problems. Stated simply, arthritis disability penetrates more aspects of life than does disability from other conditions. Arthritis-disabled individuals introduce buffers widely, but opt for types of assistance that are commonplace and maintain their self sufficiency.

This analysis concerns differentials between groups. Choosing groups for differentials involves difficult decisions, and there are often many useful and correct ways to conduct such an analysis. We designed the analyses to satisfy a variety of agency and research needs. We discuss here the value of 2 arthritis disability groups, statistics that generalize to large populations, and age-sex standardization.

Arthritis disability is presented in 2 ways in this analysis, one based on a wide range of arthritis and other rheumatic conditions (A\&RDisab) and the other on arthritis conditions only (ArthDisab). There are some differences between the 2 groups: ArthDisab persons are older; have less social participation; have more and longer ADL/IADL/ PLIM disabilities and more transportation, home access, and work problems; and have slightly more equipment and personal assistance for ADL/IADL. These differences become unimportant when the 2 groups are compared with other-disabled individuals. No matter which arthritis group we use, differentials with other-disabled individuals are essentially the same (size, direction, statistical significance). This result greatly facilitates analyses of arthritis disability. Researchers can choose either span of conditions, confident that the 2 options generate similar comparisons with other disease groups and yield similar conclusions.

We studied large real-world population groups. Nonstandardized results portray the clienteles/constituencies that health professionals encounter, agencies serve, and health policymakers must address. Simply put, they show arthritis disability as it exists day to day in the US population. Choosing big groups such as this inevitably brings in heterogeneity. The A\&RDisab and ArthDisab groups are not "arthritis only" because persons in these groups can have more disabling conditions than just arthritis. The OthDisab group is also heterogeneous; persons have disabilities due to any other condition besides arthritis. At the start of our analysis, we looked carefully at the groups. There is virtually no difference in the types of disabling conditions the respondents mentioned (except by definition, one group has arthritis conditions and the other does not). The sole perceptible difference is slightly higher reports of stroke, nervous system, and developmen- 
tal problems in the other-disabled group (this may help explain the group's higher use of vocational rehabilitation and mental health services); we reiterate that these are small differences. Average numbers of reported disabling conditions were identical for the groups. Even so, group heterogeneity reduces the chances of finding large differentials. We still found large differentials. This signals that arthritis disability is indeed distinctive in the ways we have portrayed.

Age-sex standardization removes effects that age and sex have on group differences in outcomes. Because arthritis-disabled individuals are older and more likely to be female than other-disabled individuals, differentials do change with standardization. They typically remain, but are smaller in size and have less statistical significance. The strongest nonstandardized differences remain strong and significant with standardization. Therefore, the profile of arthritis disability that we stated is true even if all groups had the same age-sex structure.

The distinctive aspect of arthritis disability is its social breadth. Arthritis-disabled individuals have problems in more areas of daily life than individuals with disability from other conditions. Arthritis-disabled individuals' ADL/IADL disabilities are more bothersome, often causing fatigue, pain, and a long time to complete tasks. The most striking single problem that arthritis-disabled individuals have is leaving their home for social activities, errands, and local events. Arthritis-disabled individuals use accommodations in more domains, emphasizing equipment use over personal assistance. They state more needs for public access and workplace accommodations. All in all, the profile of arthritis disability includes extensive and uncomfortable disabilities, yet active management strategies to handle these disabilities.

Of all disabling conditions, arthritis is the most likely prospect for each and every aging American. The impact of arthritis is on life, and often many years of it, rather than on death. Turning biomedical research and health policy toward arthritis and designing suitable accommodations for arthritis disability has real chances for enhancing older persons' productive and daily lives (45).

\section{REFERENCES}

1. Collins JG. Prevalence of selected chronic conditions: United States, 1990-92. In: Vital and Health Statistics, Series 10, No. 194. Hyattsville (MD): National Center for Health Statistics; 1997. Pub. No.: DHHS-PHS 97-1522.

2. LaPlante MP. Data on disability from the National Health Interview Survey, 1983-85. Washington: Dept. of Education (US), National Institute on Disability and Rehabilitation Research; 1988.

3. Verbrugge LM. Women, men, and osteoarthritis. Arthritis Care Res 1995;8:212-20.

4. Centers for Disease Control and Prevention. Public health and aging: projected prevalence of self-reported arthritis or chronic joint symptoms among persons aged >65 years: United States, 2005-2030. MMWR Morb Mortal Wkly Rep 2003;52:489-91.

5. Centers for Disease Control and Prevention. Prevalence of self-reported arthritis or chronic joint symptoms among adults: United States, 2001. MMWR Morb Mortal Wkly Rep 2002;51:948-50.

6. Dunlop DD, Manheim LM, Song J, Chang RW. Arthritis prev- alence and activity limitations in older adults. Arthritis Rheum 2001;44:212-21.

7. Elders MJ. The increasing impact of arthritis on public health. J Rheumatol Suppl 2000;60:6-8.

8. Feinglass J, Nelson C, Lawther T, Chang RW. Chronic joint symptoms and prior arthritis diagnosis in community surveys: implications for arthritis prevalence estimates. Public Health Rep 2003;118:230-9.

9. Helmick CG, Lawrence RC, Pollard RA, Lloyd E, Heyse SP, and the National Arthritis Data Workgroup. Arthritis and other rheumatic conditions: who is affected now, who will be affected later? Arthritis Care Res 1995;8:203-11.

10. Lawrence RC, Helmick CG, Arnett FC, Deyo RA, Felson DT, Giannini EH, et al. Estimates of the prevalence of arthritis and selected musculoskeletal disorders in the United States. Arthritis Rheum 1998;41:778-99.

11. Mili F, Helmick CG, Zack MM. Prevalence of arthritis: analysis of data from the US Behavioral Risk Factor Surveillance System, 1996-99. J Rheumatol 2002;29:1981-8.

12. Centers for Disease Control and Prevention. Prevalence of disabilities and associated health conditions among adults: United States, 1999 [published erratum appears in MMWR Morb Mortal Wkly Rep 2001;50:149]. MMWR Morb Mortal Wkly Rep 2001;50:120-5.

13. Badley EM. The impact of disabling arthritis. Arthritis Care Res 1995;8:221-8.

14. Boult C, Kane RL, Louis TA, Boult L, McCaffrey D. Chronic conditions that lead to functional limitation in the elderly. J Gerontol 1994;49:M28-36.

15. Gabriel SE, Crowson CS, Campion ME, O'Fallon WM. Indirect and nonmedical costs among people with rheumatoid arthritis and osteoarthritis compared with nonarthritic controls. J Rheumatol 1997;24:43-8.

16. Guccione AA, Felson DT, Anderson JJ, Anthony JM, Zhang Y, Wilson PW, et al. The effects of specific medical conditions on the functional limitations of elders in the Framingham Study. Am J Public Health 1994;84:351-8.

17. Guralnik JM, Kaplan GA. Predictors of healthy aging: prospective evidence from the Alameda County study. Am J Public Health 1989;79:703-8.

18. Harris T, Kovar MG, Suzman R, Kleinman JC, Feldman JJ. Longitudinal study of physical ability in the oldest-old. Am J Public Health 1989;79:698-702.

19. Hubert HB, Bloch DA, Fries JF. Risk factors for physical disability in an aging cohort: the NHANES I Epidemiologic Followup Study [published erratum appears in J Rheumatol 1994;21:177]. J Rheumatol 1993;20:480-8.

20. Hughes SL, Dunlop D. The prevalence and impact of arthritis in older persons. Arthritis Care Res 1995;8:257-64.

21. Katz PP. The impact of rheumatoid arthritis on life activities. Arthritis Care Res 1995;8:272-8.

22. Mitchell JM, Burkhauser RV, Pincus T. The importance of age, education, and comorbidity in the substantial earnings losses of individuals with symmetric polyarthritis. Arthritis Rheum 1988;31:348-57.

23. Reisine ST, Grady KE, Goodenow C, Fifield J. Work disability among women with rheumatoid arthritis: the relative importance of disease, social, work, and family factors. Arthritis Rheum 1989;32:538-43.

24. Verbrugge LM, Lepkowski JM, Konkol LL. Levels of disability among U.S. adults with arthritis. J Gerontol 1991;46:S71-83.

25. Verbrugge LM, Patrick DL. Seven chronic conditions: their impact on US adults' activity levels and use of medical services. Am J Public Health 1995;85:173-82.

26. Yelin E, Callahan LF, and the National Arthritis Data Work Group. The economic cost and social and psychological impact of musculoskeletal conditions. Arthritis Rheum 1995;38: 1351-62.

27. Boult C, Altmann M, Gilbertson D, Yu C, Kane RL. Decreasing disability in the 21st century: the future effects of controlling six fatal and nonfatal conditions. Am J Public Health 1996; 86:1388-93.

28. Centers for Disease Control and Prevention. Impact of arthritis and other rheumatic conditions on the health-care system: 
United States, 1997. MMWR Morb Mortal Wkly Rep 1999;48: 349-53.

29. Centers for Disease Control and Prevention. Direct and indirect costs of arthritis and other rheumatic conditions: United States, 1997. MMWR Morb Mortal Wkly Rep 2003;52:1124-7.

30. Crimmins EM, Kim JK, Hagedorn A. Life with and without disease: women experience more of both. J Women Aging 2002;14:47-59.

31. Felts W, Yelin E. The economic impact of the rheumatic diseases in the United States. J Rheumatol 1989;16:867-84.

32. Lubeck DP. The economic impact of arthritis. Arthritis Care Res 1995;8:304-10.

33. Murray DJ, Lopez AD, editors. The global burden of disease: a comprehensive assessment of mortality and disability from disease, injuries, and risk factors in 1990 and projected to 2020. Global Burden of Disease and Injury Series, Vol. I. Cambridge (MA): Harvard School of Public Health; 1996.

34. Reginster JY. The prevalence and burden of arthritis. Rheumatology (Oxford) 2002;41 Suppl 1:3-6.

35. Reynolds DL, Torrance GW, Badley EM, Bennett KJ, Chambers LW, Goldsmith $\mathrm{CH}$, et al. Modelling the population health impact of musculoskeletal diseases: arthritis. J Rheumatol 1993;20:1037-47.

36. Yelin E, Herrndorf A, Trupin L, Sonneborn D. A national study of medical care expenditures for musculoskeletal conditions: the impact of health insurance and managed care. Arthritis Rheum 2001;44:1160-9.

37. Arthritis Foundation, Association of State and Territorial Health Officials, Centers for Disease Control and Prevention
(US). National Arthritis Action Plan: a public health strategy. Atlanta (GA): The Foundation; 1999.

38. US Department of Health and Human Services. Tracking healthy people 2010. Washington (DC): US Government Printing Office; 2000.

39. Verbrugge LM, Juarez L. Profile of arthritis disability. Public Health Rep 2001;116 Suppl 1:157-79.

40. Adams PF, Marano MA. Current estimates from the National Health Interview Survey, 1994. Vital and Health Statistics, Series 10, No. 193. Hyattsville (MD): National Center for Health Statistics (US); 1995. Pub. No.: DHHS-PHS 96-1521.

41. Massey JT, Moore TF, Parsons VL, Tadros W. Design and estimation for the National Health Interview Survey, 19851994. Vital and Health Statistics, Series 2, No. 111. Hyattsville (MD): National Center for Health Statistics (US); 1989. Pub. No.: DHHS-PHS 89-1384.

42. Shah BV, Barnwell BG, Bieler GS. SUDAAN Software for the Statistical Analysis of Correlated Data: user's manual, Vol. 1,2. Release 7.5. Research Triangle Park (NC): Research Triangle Institute; 1997. URL: http://www.rti.org/sudaan/.

43. Verbrugge LM, Jette AM. The disablement process. Soc Sci Med 1994;38:1-14.

44. Kono A, Kai I, Sakato C, Rubenstein LZ. Frequency of going outdoors: a predictor of functional and psychosocial change among ambulatory frail elders living at home. J Gerontol A Biol Sci Med Sci 2004;59:M275-80.

45. Kirschstein R. Disease-specific estimates of direct and indirect costs of illness and NIH support: fiscal year 2000 update. Bethesda (MD): Department of Health and Human Services, National Institutes of Health, Office of the Director; 2000. 